\title{
Randomized clinical trial of adjuvant chemotherapy with intraperitoneal and intravenous cisplatin followed by oral fluorouracil (UFT) in serosa-positive gastric cancer versus curative resection alone: final results of the Japan Clinical Oncology Group trial JCOG9206-2
}

\author{
Isao Miyashiro $\cdot$ Hiroshi Furukawa $\cdot$ Mitsuru Sasako $\cdot$ Seiichiro Yamamoto $•$ \\ Atsushi Nashimoto • Toshifusa Nakajima • Taira Kinoshita • Osamu Kobayashi • \\ Kuniyoshi Arai - The Gastric Cancer Surgical Study Group in the Japan Clinical Oncology Group
}

Received: 9 October 2010/Accepted: 15 December 2010/Published online: 19 February 2011

(C) The International Gastric Cancer Association and The Japanese Gastric Cancer Association 2011

\begin{abstract}
Purpose To evaluate the survival benefit of adjuvant chemotherapy after curative resection in serosa-positive gastric cancer, a multicenter phase III clinical trial was conducted in Japan.

Patients and methods From January 1993 to March 1998, 268 patients were randomized to adjuvant chemotherapy (135 patients) or surgery alone (133 patients). All patients underwent gastrectomy with D2 or greater lymph node dissection. The chemotherapy regimen consisted of intraperitoneal cisplatin soon after abdominal closure, postoperative intravenous cisplatin (day 14) and 5-fluorouracil (day 14-16), and daily oral FU (UFT) starting 4 weeks
\end{abstract}

Presented at: 2005 Gastrointestinal Cancers Symposium (ASCO-GI), Hollywood, FL, January 2005.

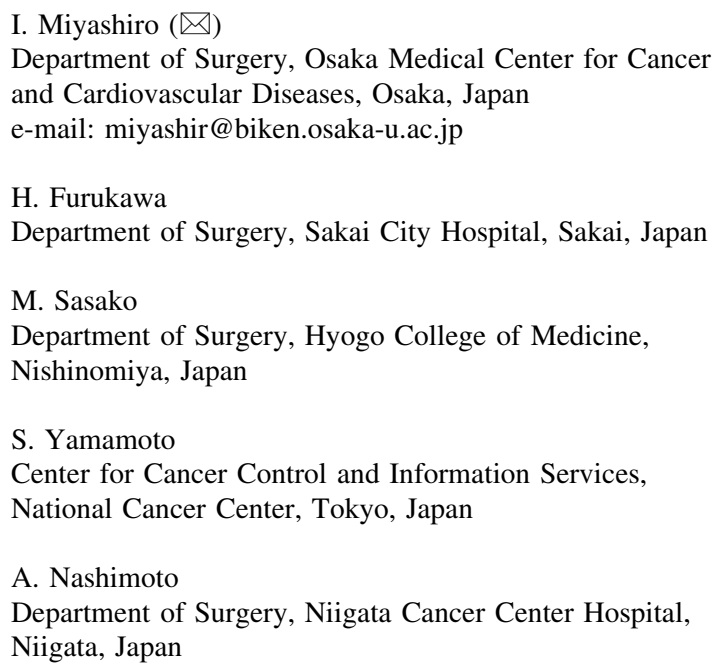

after surgery for 12 months. The primary endpoint was overall survival. Relapse-free survival and site of recurrence were secondary endpoints.

Results Fifty-two patients $(38.5 \%)$ in the adjuvant chemotherapy arm completed the chemotherapy regimen. There were $4(1.49 \%)$ treatment-related deaths, 1 in the surgery-alone and 3 in the adjuvant chemotherapy arm (2 did not receive chemotherapy). Grade 4 toxicity was observed in 3 patients in the surgery-alone and 2 patients in the adjuvant chemotherapy arm. There was no significant difference in 5-year overall survival (62.0\% adjuvant chemotherapy vs. $60.9 \%$ surgery-alone, $P=0.482$ ) and 5 -year relapse-free survival rates $(57.5 \%$ adjuvant chemotherapy vs. $55.6 \%$ surgery-alone; $P=0.512$ ).

Conclusion There was no benefit in overall and relapsefree survival with this adjuvant chemotherapy regimen for

T. Nakajima

Department of Surgery, Cancer Institute Hospital, Tokyo, Japan

\section{T. Kinoshita}

Department of Surgery, National Cancer Center Hospital East,

Kashiwa, Japan

O. Kobayashi

Department of Surgery, Kanagawa Cancer Center,

Yokohama, Japan

K. Arai

Department of Surgery, Tokyo Metropolitan Komagome

Hospital, Tokyo, Japan 
patients with macroscopically serosa-positive gastric cancer after curative resection.

Keywords Randomized clinical trial $\cdot$ Adjuvant chemotherapy - Serosa-positive gastric cancer . Intraperitoneal chemotherapy

\section{Introduction}

A large number of gastric cancers are still diagnosed in advanced stages worldwide [1,2]. Once the primary tumor invades the subserosal or serosal layers of the gastric wall, cancer cells are more likely to spread into the abdominal cavity and implant on peritoneal surfaces, resulting in peritoneal dissemination [3,4]. The most frequent cause of recurrence and subsequent cancer death in serosa-positive gastric cancer is peritoneal metastasis even after curative resection [5-7]. The main goal of adjuvant chemotherapy for resected gastric cancer is to prevent such a distant recurrence and increase the potential of cure.

In Japan today, adjuvant chemotherapy with single agent $\mathrm{S}-1$ is considered the standard of care for patients with pathological stage II/III (Japanese Classification of Gastric Carcinoma 2nd English Edition [8, 9]) gastric cancer after potentially curative D2 dissection, based on the results of the ACTS-GC clinical trial [10-13]. However, subgroup analysis of the ACTS-GC data suggest that S-1 may be less effective for patients with more advanced gastric cancer such as serosa-positive cancer.

The present Japan Clinical Oncology Group (JCOG) trial, JCOG9206-2, is a randomized controlled phase III clinical trial of adjuvant chemotherapy with intraperitoneal and intravenous cisplatin followed by oral fluorouracil (FU). Thirteen institutions in Japan participated in this trial as members of the Gastric Cancer Surgical Study Group (GCSSG), a subgroup of JCOG [14]. We report here the final results with 6 years of follow-up.

\section{Patients and methods}

\section{Patients}

Patients had to fulfill the following eligibility criteria: macroscopically complete operation; histologically proven gastric adenocarcinoma, macroscopically serosa-positive (T3-4), with no metastases to level 3-4 lymph node stations (N0-2) $[8,9]$; age 75 years or younger; no previous treatment for gastric cancer; negative peritoneal lavage cytology; adequate organ function as assessed by laboratory studies: leukocyte count of at least $4000 / \mathrm{mm}^{3}$; hemoglobin of at least $11.0 \mathrm{~g} / \mathrm{dl}$; platelet count of at least
$100000 / \mathrm{mm}^{3}$; AST, ALT, total bilirubin, blood urea nitrogen and creatinine no higher than 1.25 times the upper limit of normal; creatinine clearance no lower than $70 \mathrm{ml} / \mathrm{min}$. All patients provided written informed consent. Patients who had undergone any chemotherapy or radiotherapy, or those with synchronous or metachronous cancer of other organs were excluded.

Treatment assignment and evaluation

The patients were randomized using the minimization method to balance the adjuvant chemotherapy and surgeryalone arms according to institution and the combination of the macroscopic depth of tumor invasion (T-category) and lymph node metastasis ( $\mathrm{N}$-category) according to the Japanese Classification of Gastric Carcinoma 2nd English Edition [9]. After the surgeon confirmed the above eligibility criteria, patients were randomly assigned to either arm by means of an intraoperative telephone call to the JCOG Data Center (Fig. 1).

The chemotherapy comprised intraperitoneal cisplatin $\left(70 \mathrm{mg} / \mathrm{m}^{2}\right)$ soon after abdominal closure; intravenous cisplatin $\left(70 \mathrm{mg} / \mathrm{m}^{2}\right)$ on postoperative day 14 ; intravenous 5 -fluorouracil (5-FU) $\left(700 \mathrm{mg} / \mathrm{m}^{2}\right)$ daily on postoperative days 14-16; and UFT $\left(267 \mathrm{mg} / \mathrm{m}^{2}\right)$ daily, starting 4 weeks after surgery for 12 months. Intraperitoneal cisplatin $\left(70 \mathrm{mg} / \mathrm{m}^{2}\right.$ with saline in total volume $\left.1000 \mathrm{ml}\right)$ was administered via drainage tubes that were clamped for following $2 \mathrm{~h}$. Creatinine clearance was evaluated twice weekly before and after the administration of cisplatin. A full blood count was performed every week to assess for hematological toxicity during hospital stay. During UFT treatment, each patient was asked to visit the hospital every month for physical examinations and laboratory testing in both arms. Patients underwent upper gastrointestinal series, gastric endoscopy, ultrasonography, computed tomography or other investigations either as required or every 6 months

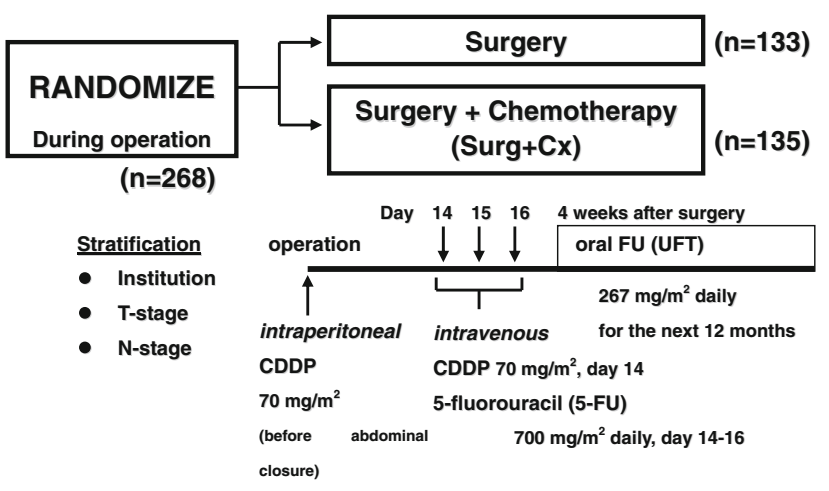

Fig. 1 Study scheme. All patients underwent gastrectomy with D2 or greater lymph node dissection. CDDP, cis-diamminedichloro-platinum (cisplatin) 
to evaluate for recurrence. Adverse events were recorded according to the JCOG toxicity criteria [15]. Since some adverse events may occur after surgery even without chemotherapy, all potential adverse drug effects were compared with the adverse effects experienced by patients in the surgery-alone arm. Data on adverse events in the surgery-alone patients, except for postoperative morbidity and mortality, were collected retrospectively. Original case report forms were designed to collect adverse events during chemotherapy (only in the adjuvant chemotherapy arm). However, some adverse events happened even in the surgery-alone group. To keep the comparability between arms, we re-collected the data of adverse events from both arms at the final analysis. The surgery-alone arm received no additional treatment after surgery unless there was recurrence. The main prognostic factors, including age, gender, the depth of tumor invasion and nodal spread, operative procedures, and pathological findings, were described according to the general guidelines issued by the Japanese Research Society for Gastric Cancer Study [8, 9].

Study design and statistical analyses

This study was designed as a multicenter prospective randomized controlled phase III clinical trial. The study protocol was approved by the JCOG Clinical Trial Review
Committee and the institutional review boards of all participating institutions. The primary endpoint was OS. Relapse-free survival and the site of recurrence were secondary endpoints. The original planned duration of accrual was 4 years with 5 years of follow-up. The planned sample size was 280 patients, with 140 patients in each arm to power the study at $80 \%$ to detect a $15 \%$ difference in 5 -year OS rates between the surgery-alone arm (40\%) and the chemotherapy arm (55\%) with a two-sided significance level of $5 \%$. The study design was amended to one projecting 5-year OS rates of 55\% in the surgery-alone arm and $67 \%$ in the chemotherapy arm, with a 5-year accrual period and 6 years follow-up, because combined survival was better, and accrual poorer, than expected.

OS was measured from the date of random treatment assignment to the date of death or censored at the date of the last follow-up. Relapse-free survival was measured from the date of random treatment assignment to the date of the first observation of relapse or the date of death from any cause. If no progression was reported and if the patient remained alive, data on relapse-free survival were censored as of the date on which the absence of relapse was confirmed. OS and relapse-free survival were estimated by the Kaplan-Meier method and compared by the stratified logrank test with the combination of the depth of the tumor invasion and lymph node metastasis as strata on the

Fig. 2 CONSORT diagram

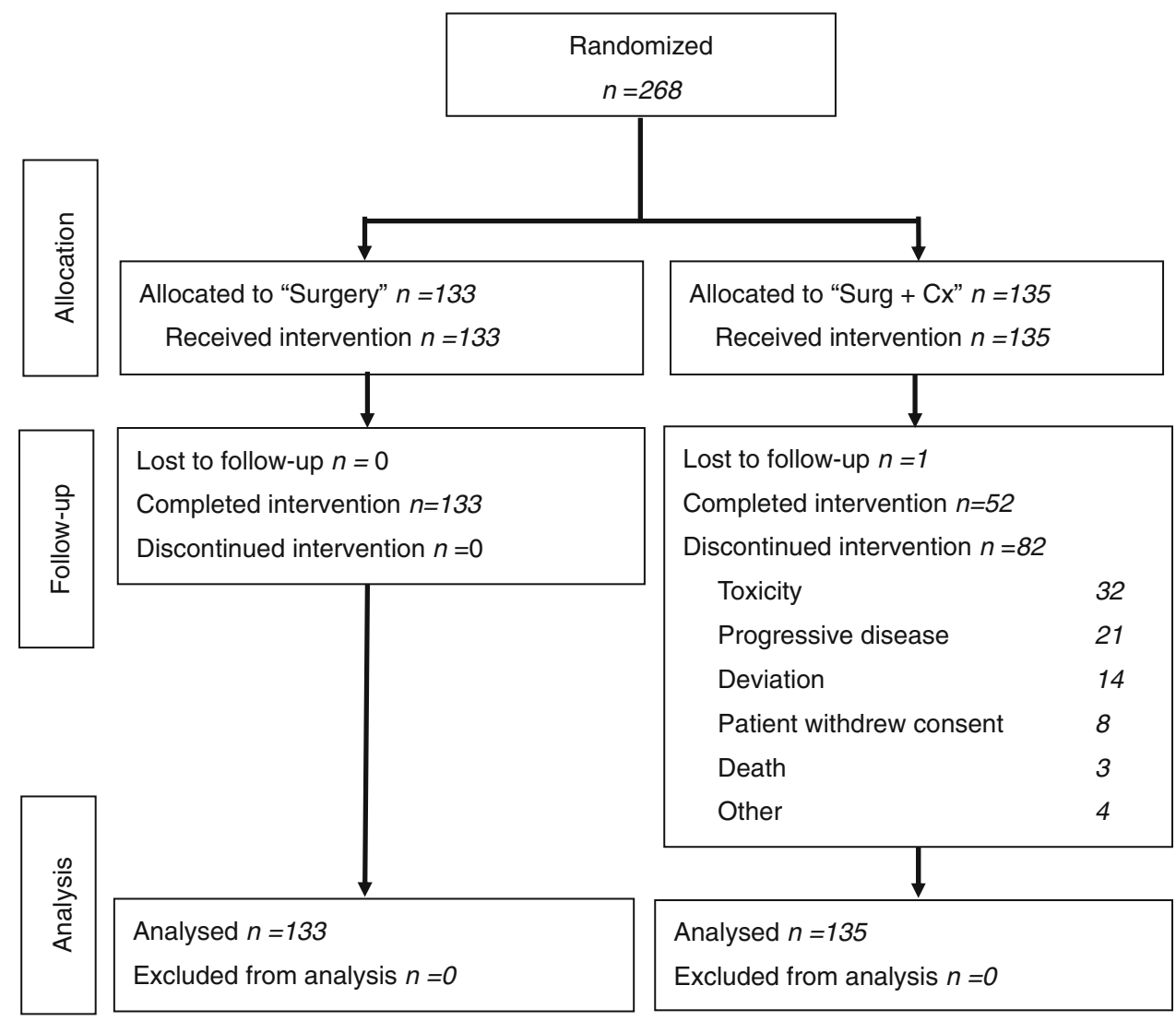


Table 1 Distribution of the main prognostic factors in the two treatment arms

\begin{tabular}{|c|c|c|c|}
\hline No. of patients & $\begin{array}{l}\text { Surgery } \\
(n=133)\end{array}$ & $\begin{array}{l}\text { Surg }+C x \\
(n=135)\end{array}$ & $P^{*}$ \\
\hline Gender & & & 0.601 \\
\hline Male & 88 & 94 & \\
\hline Female & 45 & 41 & \\
\hline Age (years) & & & 0.043 \\
\hline Median & 57 & 59 & \\
\hline Range & $23-73$ & $33-75$ & \\
\hline Tumor diameter $(\mathrm{cm})$ & & & 0.324 \\
\hline Median & 5.5 & 6.0 & \\
\hline Range & $2.4-19.0$ & $1.5-18.0$ & \\
\hline Macroscopic type & & & 0.603 \\
\hline 0 & 0 & 0 & \\
\hline 1 & 5 & 1 & \\
\hline 2 & 31 & 32 & \\
\hline 3 & 76 & 78 & \\
\hline 4 & 14 & 15 & \\
\hline 5 & 7 & 9 & \\
\hline Liver metastasis & & & - \\
\hline Absent (H0) & 133 & 135 & \\
\hline Present $(\mathrm{H} 1)$ & 0 & 0 & \\
\hline $\begin{array}{l}\text { Peritoneal metastasis } \\
\quad \text { (macroscopic) }\end{array}$ & & & 0.245 \\
\hline Absent (P0) & 131 & 135 & \\
\hline Present (P1) & 2 & 0 & \\
\hline Type of gastrectomy & & & 1.000 \\
\hline Total & 76 & 76 & \\
\hline Proximal & 0 & 1 & \\
\hline Distal & 57 & 58 & \\
\hline Combined resection & & & 0.787 \\
\hline No & 39 & 37 & \\
\hline Yes & 94 & 98 & \\
\hline Spleen & 73 & 74 & \\
\hline Pancreas & 26 & 26 & \\
\hline Adrenal gland & 7 & 5 & \\
\hline Colon & 6 & 6 & \\
\hline Other & 50 & 50 & \\
\hline $\begin{array}{l}\text { Pathological depth of tumor } \\
\text { invasion }(\mathrm{T})\end{array}$ & & & 0.613 \\
\hline \multicolumn{4}{|l|}{$\mathrm{T} 1$} \\
\hline $\mathrm{m}, \mathrm{sm}$ & 2 & 3 & \\
\hline \multicolumn{4}{|l|}{$\mathrm{T} 2$} \\
\hline $\mathrm{mp}$ & 5 & 7 & \\
\hline \multicolumn{4}{|l|}{$\mathrm{T} 2$} \\
\hline ss & 34 & 41 & \\
\hline \multicolumn{4}{|l|}{$\mathrm{T} 3$} \\
\hline se & 88 & 77 & \\
\hline \multicolumn{4}{|l|}{$\mathrm{T} 4$} \\
\hline si & 4 & 7 & \\
\hline
\end{tabular}

Table 1 continued

\begin{tabular}{|c|c|c|c|}
\hline No. of patients & $\begin{array}{l}\text { Surgery } \\
(n=133)\end{array}$ & $\begin{array}{l}\text { Surg }+ \text { Cx } \\
(n=135)\end{array}$ & $P^{*}$ \\
\hline $\begin{array}{l}\text { Pathological extent of lymph } \\
\text { node metastasis }(\mathrm{N})^{\mathrm{a}}\end{array}$ & & & 0.794 \\
\hline No & 32 & 41 & \\
\hline $\mathrm{N} 1$ & 51 & 49 & \\
\hline $\mathrm{N} 2$ & 38 & 35 & \\
\hline $\mathrm{N} 3$ & 5 & 4 & \\
\hline N4 & 7 & 5 & \\
\hline \multicolumn{4}{|c|}{ Involvement of the resection margin } \\
\hline Proximal & & & 1.000 \\
\hline Negative & 133 & 134 & \\
\hline Positive & 0 & 1 & \\
\hline Distal & & & 0.498 \\
\hline Negative & 133 & 133 & \\
\hline Positive & 0 & 2 & \\
\hline Tumor histology & & & 0.991 \\
\hline \multicolumn{4}{|l|}{ Common types } \\
\hline Papillary & 1 & 2 & \\
\hline Well differentiated & 10 & 12 & \\
\hline Moderately differentiated & 33 & 35 & \\
\hline Poorly differentiated & 69 & 67 & \\
\hline Mucinous & 6 & 5 & \\
\hline Signet ring cell & 13 & 13 & \\
\hline \multicolumn{4}{|l|}{ Other types } \\
\hline Carcinoid & 1 & 0 & \\
\hline Unknown & 0 & 1 & \\
\hline
\end{tabular}

Surg $+C x$ Surgery plus adjuvant chemotherapy, $m$ mucosa including muscularis mucosae, $s m$ submucosa, $m p$ muscularis propria, $s s$ subserosal, $s$ serosa, si serosa-infiltrating

* A $t$-test was used for continuous variables. Fisher's exact test was used for discrete variables

a Pathological extent of lymph node metastasis was classified based on the Japanese Classification of Gastric Carcinoma 1st English edition. Data are missing for one patient in the Surg $+\mathrm{Cx}$ arm

intention-to-treat basis. Analyses for toxicity were conducted for all of the randomly assigned patients. All statistical analyses were conducted with SAS software (version 8.1, SAS Institute, Cary, NC).

\section{Results}

From January 1993 to March 1998, 268 patients were enrolled in this phase III study. Of the 268 eligible patients enrolled, 133 patients were assigned to the surgery-alone arm and 135 patients to the adjuvant chemotherapy arm (Fig. 2). Distribution of the main prognostic factors across the two arms was well balanced (Table 1). There were no significant differences between the two groups in the 
Table 2 Frequency of postoperative morbidity and mortality

\begin{tabular}{lccc}
\hline & $\begin{array}{l}\text { Surgery } \\
(n=133)\end{array}$ & $\begin{array}{l}\text { Surg }+\mathrm{Cx} \\
(n=135)\end{array}$ & $P$ \\
\hline Surgical morbidity & & & \\
$\quad$ Leakage & 3 & 9 & 0.137 \\
Pancreatic fistula & 20 & 14 & 0.275 \\
Peritoneal abscess & 8 & 13 & 0.364 \\
Pneumonia & 3 & 1 & 0.369 \\
Other infections & 9 & 6 & 0.439 \\
Stomal stenosis & 2 & 1 & 0.621 \\
Ileus & 0 & 4 & 0.122 \\
Miscellaneous & 4 & 16 & 0.009 \\
Non-surgical morbidity & & 21 & $<0.001$ \\
Creatinine $\geq 2.0$ & 3 & 43 & 0.896 \\
AST, ALT $\geq 100$ & 44 & 4 & 0.370 \\
Hospital death & 1 & & \\
\hline
\end{tabular}

Surg $+C x$ Surgery plus adjuvant chemotherapy

institution and the combination of macroscopic T-category and $\mathrm{N}$-category as stratification factors. There were also no significant differences in gender, but the surgery-alone group was younger than the adjuvant chemotherapy group $(P=0.0426)$. All patients underwent gastrectomy with $\mathrm{D} 2$ or greater lymph node dissection. The operative procedures were similar in the two groups. Seventy-six of 133 patients $(57.1 \%)$ in the surgery-alone arm and 76 of $135(56.3 \%)$ in the adjuvant chemotherapy arm underwent total gastrectomy, and all the other patients except one underwent distal gastrectomy. Similar numbers of patients in each group underwent combined resections involving the spleen, pancreas, adrenal gland, colon or other organs. There were no significant differences between the two groups in tumor diameter, macroscopic type, presence of liver or macroscopic peritoneal metastasis, depth of tumor invasion, extent of lymph node metastasis, involvement of the resection margins and histological type.

Of the 135 patients of the adjuvant chemotherapy arm, 82 patients discontinued chemotherapy as is shown in Fig. 2. Thirty-two patients discontinued chemotherapy because of toxicity, among whom 19 patients could not start intravenous chemotherapy. Therefore, only the remaining 13 patients terminated chemotherapy during intravenous CDDP/5-FU or oral UFT.

The perioperative mortality was low. There were 4 treatment-related deaths. One of 133 patients in the surgery-alone arm died because of postoperative complications, and 3 of 135 in the adjuvant chemotherapy arm died because of postoperative complications or chemotherapy toxicity ( 2 of 3 did not receive chemotherapy). There were no significant differences in the frequency of surgical morbidity except for miscellaneous events such as wound
Table 3 Adverse events

\begin{tabular}{|c|c|c|c|c|c|c|c|}
\hline \multirow[t]{2}{*}{$\overline{\text { Arm }}$} & \multicolumn{5}{|c|}{ Grade $^{a}$} & \multirow{2}{*}{$\begin{array}{l}\% \\
\text { Grade } 4\end{array}$} & \multirow[t]{2}{*}{ Tota } \\
\hline & 0 & 1 & 2 & 3 & 4 & & \\
\hline \multicolumn{8}{|l|}{ Surgery } \\
\hline Leukopenia & 90 & 28 & 9 & 0 & 0 & 0 & 127 \\
\hline Anemia & 58 & 31 & 34 & 4 & - & - & 127 \\
\hline Thrombocytopenia & 125 & 1 & 1 & 0 & 0 & 0 & 127 \\
\hline Increase in bilirubin & 83 & - & 32 & 11 & 1 & 0.8 & 127 \\
\hline Increase in AST & 22 & 62 & 27 & 14 & 2 & 1.6 & 127 \\
\hline Increase in ALT & 26 & 55 & 29 & 16 & 1 & 0.8 & 127 \\
\hline Increase in creatinine & 109 & 13 & 4 & 1 & 0 & 0 & 127 \\
\hline Nausea or vomiting & 110 & 16 & 4 & 0 & 0 & 0 & 130 \\
\hline Diarrhea & 122 & 6 & 2 & 0 & 0 & 0 & 130 \\
\hline Stomatitis & 129 & 1 & 0 & 0 & 0 & 0 & 130 \\
\hline Neuropathy (sensory) & 130 & 0 & 0 & 0 & 0 & 0 & 130 \\
\hline Skin-other (pigmentation) & 130 & 0 & 0 & 0 & 0 & 0 & 130 \\
\hline \multicolumn{8}{|l|}{ Surg $+\mathrm{Cx}$} \\
\hline Leukopenia & 76 & 30 & 19 & 3 & 1 & 0.8 & 129 \\
\hline Anemia & 31 & 24 & 56 & 18 & - & - & 129 \\
\hline Thrombocytopenia & 123 & 4 & 1 & 0 & 1 & 0.8 & 129 \\
\hline Increase in bilirubin & 67 & - & 43 & 15 & 1 & 0.8 & 126 \\
\hline Increase in AST & 25 & 61 & 27 & 16 & 0 & 0 & 129 \\
\hline Increase in ALT & 29 & 70 & 21 & 9 & 0 & 0 & 129 \\
\hline Increase in creatinine & 70 & 38 & 16 & 5 & 0 & 0 & 129 \\
\hline Nausea or vomiting & 80 & 31 & 19 & 1 & 0 & 0 & 131 \\
\hline Diarrhea & 113 & 17 & 1 & 0 & 0 & 0 & 131 \\
\hline Stomatitis & 126 & 4 & 1 & 0 & 0 & 0 & 131 \\
\hline Neuropathy (sensory) & 128 & 3 & 0 & 0 & 0 & 0 & 131 \\
\hline Skin-other (pigmentation) & 130 & 1 & 0 & 0 & 0 & 0 & 131 \\
\hline
\end{tabular}

Surg $+C x$ Surgery plus adjuvant chemotherapy

a Toxicity graded according to JCOG criteria [13]

infection (Table 2). As for postoperative non-surgical morbidity, renal dysfunction (JCOG grade 3-4) within 3 months after surgery was observed only in 5 patients in the adjuvant chemotherapy group. Adverse events were generally mild. The frequencies of adverse events according to JCOG criteria are listed in Table 3 . Grade 4 toxicity was observed in 3 patients in the surgery-alone and 2 patients in adjuvant chemotherapy arm.

In 6 years of planned follow-up, there was no significant differences in OS (Fig. 3) and relapse-free survival (Fig. 4). The 5-year overall survival rate in the adjuvant chemotherapy arm was $62.0 \%$ (95\% confidence interval $53.7-70.2)$ versus $60.9 \%(52.6-69.2)$ in the surgery-alone arm $(P=0.482$, one-sided stratified log-rank test). The 5 -year relapse-free survival rate was $57.5 \%(49.1-65.9)$ in the adjuvant chemotherapy group versus $55.6 \%$ (47.2$64.1)$ in the surgery-alone group $(P=0.512)$ one-sided stratified log-rank test). Sixty-six of 135 patients $(48.9 \%)$ in the adjuvant chemotherapy arm and 64 of 133 patients 


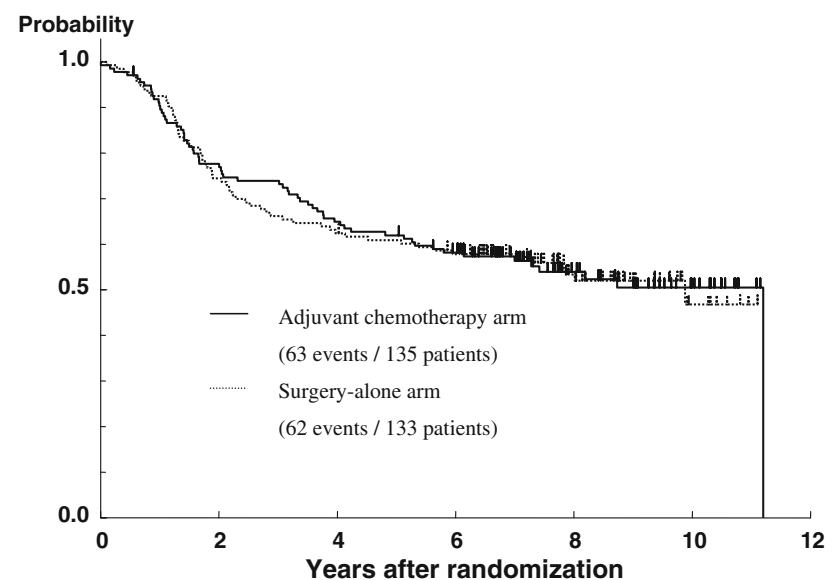

Fig. 3 Overall survival. There was no significant difference in overall survival: 5 -year survival rate $62.0 \%$ (95\% confidence interval $53.7-70.2)$ in the adjuvant chemotherapy group versus $60.9 \%$ (52.6-69.2) in the surgery-alone group, $P=0.482$

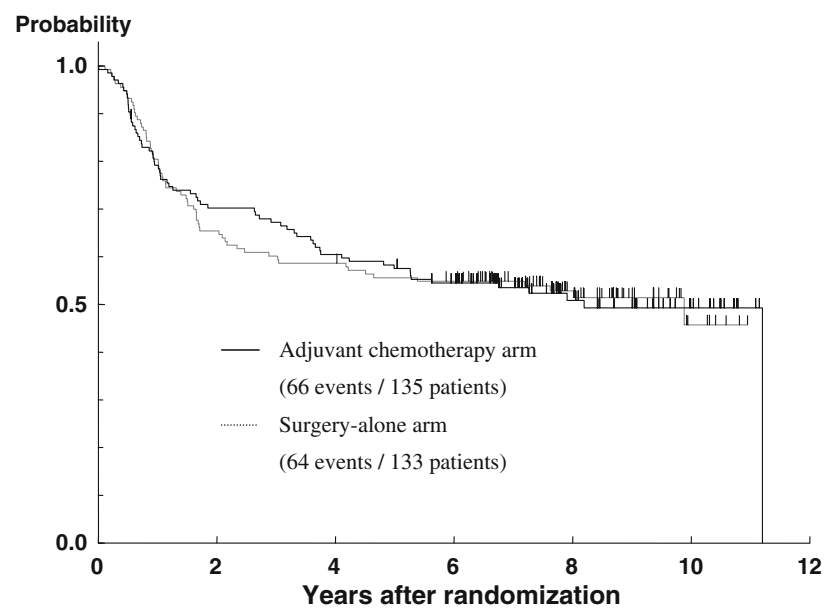

Fig. 4 Relapse-free survival. There was no significant difference in relapse-free survival: 5-year relapse-free survival rate 57.5\% (95\% confidence interval 49.1-65.9) in the adjuvant chemotherapy group versus $55.6 \%(47.2-64.1)$ in the surgery-alone group, $P=0.512$

$(48.1 \%)$ in the surgery-alone arm experienced cancer recurrence or death. The results for survival were not substantially changed after adjustment for age by Cox proportional hazards regression. Sites of recurrence, including peritoneal dissemination as the most common site, did not differ significantly between the two arms (Table 4).

\section{Discussion}

The present study is a prospective randomized controlled phase III clinical trial of adjuvant chemotherapy with cisplatin followed by UFT conducted by the GCSSG subgroup of JCOG to clarify the efficacy of adjuvant
Table 4 Site of cancer recurrence

\begin{tabular}{lccr}
\hline Site of recurrence & $\begin{array}{l}\text { Surgery } \\
(n=133)\end{array}$ & $\begin{array}{l}\text { Surg }+ \text { Cx } \\
(n=135)\end{array}$ & Total \\
\hline Peritoneal dissemination & 23 & 19 & 42 \\
Liver metastases & 9 & 16 & 25 \\
Metastases to other organs & 5 & 7 & 12 \\
Local (remnant stomach) & 0 & 2 & 2 \\
Local (other sites) & 4 & 2 & 6 \\
Distant lymph nodes & 10 & 6 & 16 \\
Other & 5 & 0 & 5 \\
Death before recurrence & 8 & 14 & 22 \\
Total & 64 & 66 & 130 \\
\hline
\end{tabular}

Surg $+C x$ Surgery plus adjuvant chemotherapy

chemotherapy after curative resection with extended (D2 or greater) lymphadenectomy for macroscopically serosapositive gastric cancer. There was no benefit in overall and relapse-free survival with this regimen, and there was no difference between the arms in the site of recurrence. The frequency of postoperative morbidity was similar in the two groups, suggesting that administration of intraperitoneal cisplatin does not affect postoperative morbidity [16].

The recent AMC 0101 trial demonstrated that adjuvant chemotherapy with intraperitoneal cisplatin and early mitomycin-C plus long-term doxifluridine plus cisplatin (iceMFP) improved survival of patients with grossly serosa-positive advanced gastric cancer when compared with mitomycin-C plus short-term doxifluridine (Mf) [17]. Another Korean randomized trial, AMC 0201, showed there was no benefit in survival with adjuvant mitomycin-C plus long-term doxifluridine plus cisplatin when compared with Mf [18]. Taken together, these two studies suggest that improved OS might have been due to intraperitoneal cisplatin and/or mitomycin-C when given early. However, the AMC 0101 trial could not definitively demonstrate whether intraperitoneal chemotherapy itself contributed to improved survival. The adjuvant chemotherapy in the present study might be insufficient because it consisted of just one single course of intravenous cisplatin/5-FU. However, in the AMC 0201 trial, repeated administration of doxifluridine plus cisplatin did not show any benefit over short-term mitomycin-C plus doxifluridine.

Only $39 \%$ in the adjuvant chemotherapy arm actually completed the chemotherapy regimen in the present study, although UFT toxicity was generally mild. Patients tend to suffer from gastrointestinal disturbances after gastrectomy even without postoperative chemotherapy. Compliance of highly toxic regimens significantly decreases if given in early postoperative period, as observed in the MAGIC trial, which demonstrated the superiority in overall survival of pre- and postoperative chemotherapy compared with 
surgery-alone [19]. The MAGIC trial reported that $57 \%$ of patients in the chemotherapy group were able to receive postoperative chemotherapy and that only $43 \%$ of patients in the chemotherapy group actually completed the full 6 cycles, although $88 \%$ of patients completed the 3 cycles of neoadjuvant chemotherapy. Thus, special consideration should be given to compliance when choosing a regimen for postoperative adjuvant chemotherapy. Powerful regimens should be planned for neoadjuvant settings in more advanced disease and less toxic drugs for postoperative use for earlier stage disease, such as stage II [12, 20, 21].

In conclusion, there was no benefit in overall and relapse-free survival with adjuvant cisplatin followed by UFT for patients with macroscopically serosa-positive gastric cancer after curative resection. When recurrence occurs, there was no difference in the site between the two treatment groups. Therefore, we do not recommend adjuvant chemotherapy with this regimen for this patient population in clinical practice.

Acknowledgments The authors thank Ms. Hongo, Ms. Takeuchi, and Ms. Kaba for data management; Ms. Sugimoto for secretarial assistance; Dr. Kenichi Nakamura for his intensive correction of the manuscript, and Dr. Haruhiko Fukuda for his direction of the JCOG Data Center and oversight of the management of the study. This study was supported partly by grants for Cancer Research and the SecondTerm Comprehensive 10-year Strategy for Cancer Control from the Japanese Ministry of Health, Labor, and Welfare (ClinicalTrials.gov Identifier: NCT00147147). We thank the following participating hospitals as members of the Gastric Cancer Surgical Study Group: Niigata Cancer Center Hospital, Niigata; Cancer Institute Hospital, Tokyo; National Cancer Center Hospital East, Kashiwa; Kanagawa Cancer Center, Yokohama; Tokyo Metropolitan Komagome Hospital, Tokyo; Osaka Medical Center for Cancer and Cardiovascular Diseases, Osaka; National Cancer Center Hospital, Tokyo; Aichi Cancer Center Hospital, Nagoya; National Sendai Hospital, Sendai; Miyagi Cancer Center Hospital, Natori; National Shikoku Cancer Center, Matsuyama; National Nagoya Hospital, Nagoya; Saitama Cancer Center Hospital, Saitama. The authors declare no conflict of interest.

\section{References}

1. Pisani P, Parkin DM, Bray F, Ferlay J. Estimates of the worldwide mortality from 25 cancers in 1990. Int J Cancer. 1999;83(1):18-29.

2. Wanebo HJ, Kennedy BJ, Chmiel J, Steele G Jr, Winchester D, Osteen R. Cancer of the stomach. A patient care study by the American College of Surgeons. Ann Surg. 1993;218(5):583-92.

3. Miyashiro I, Takachi K, Doki Y, Ishikawa O, Ohigashi H, Murata $\mathrm{K}$, et al. When is curative gastrectomy justified for gastric cancer with positive peritoneal lavage cytology but negative macroscopic peritoneal implant? World J Surg. 2005;29(9):1131-4.

4. Burke EC, Jr. Karpeh MS, Conlon KC, Brennan MF. Peritoneal lavage cytology in gastric cancer: an independent predictor of outcome. Ann Surg Oncol. 1998;5(5):411-5.

5. Gunderson LL, Sosin H. Adenocarcinoma of the stomach: areas of failure in a re-operation series (second or symptomatic look) clinicopathologic correlation and implications for adjuvant therapy. Int J Radiat Oncol Biol Phys. 1982;8(1):1-11.
6. Hiratsuka M, Iwanaga T, Furukawa H, Yasuda T, Nakano H, Nakamori $\mathrm{S}$, et al. Important prognostic factors in surgically treated gastric cancer patients. Gan To Kagaku Ryoho. 1995; 22(5):703-8.

7. Landry J, Tepper JE, Wood WC, Moulton EO, Koerner F, Sullinger J. Patterns of failure following curative resection of gastric carcinoma. Int J Radiat Oncol Biol Phys. 1990;19(6):1357-62.

8. Japanese Research Society for Gastric Cancer. Japanese Classification of Gastric Carcinoma. 1st English ed. Tokyo: Kanehara; 1995.

9. Japanese Gastric Cancer Association. Japanese Classification of Gastric Carcinoma-2nd English edition. Gastric Cancer. 1998; 1(1): 10-24

10. Sakuramoto S, Sasako M, Yamaguchi T, Kinoshita T, Fujii M, Nashimoto A, et al. Adjuvant chemotherapy for gastric cancer with S-1, an oral fluoropyrimidine. $\mathrm{N}$ Engl $\mathrm{J}$ Med. 2007;357(18):1810-20.

11. Nakajima T, Nashimoto A, Kitamura M, Kito T, Iwanaga T, Okabayashi K, et al. Adjuvant mitomycin and fluorouracil followed by oral uracil plus tegafur in serosa-negative gastric cancer: a randomised trial. Gastric Cancer Surgical Study Group. Lancet. 1999;354(9175):273-7.

12. Nashimoto A, Nakajima T, Furukawa H, Kitamura M, Kinoshita T, Yamamura Y, et al. Randomized trial of adjuvant chemotherapy with mitomycin, fluorouracil, and cytosine arabinoside followed by oral fluorouracil in serosa-negative gastric cancer: Japan Clinical Oncology Group 9206-1. J Clin Oncol. 2003;21(12):2282-7.

13. Nakajima T. Gastric cancer treatment guidelines in Japan. Gastric Cancer. 2002;5(1):1-5.

14. Shimoyama M, Fukuda H, Saijo N, Yamaguchi N. Japan Clinical Oncology Group (JCOG). Jpn J Clin Oncol. 1998;28(3):158-62.

15. Tobinai K, Kohno A, Shimada Y, Watanabe T, Tamura T, Takeyama K, et al. Toxicity grading criteria of the Japan Clinical Oncology Group. The Clinical Trial Review Committee of the Japan Clinical Oncology Group. Jpn J Clin Oncol. 1993;23(4): $250-7$.

16. Sano T, Katai H, Sasako M, Maruyama K. One thousand consecutive gastrectomies without operative mortality. Br J Surg. 2002;89(1):123.

17. Kang Y, Chang H, Zang D, Lee J, Kim T, Yang D, et al. Postoperative adjuvant chemotherapy for grossly serosa-positive advanced gastric cancer: a randomized phase III trial of intraperitoneal cisplatin and early mitomycin-C plus long-term doxifluridine plus cisplatin (iceMFP) versus mitomycin-C plus shortterm doxifluridine (Mf) (AMC0101) (NCT00296322). J Clin Oncol. 2008;26(15s; ASCO annual meeting abstract LBA4511).

18. Chang H, Kang Y, Min Y, Zang D, Kim G, Yang D, et al. A randomized phase III trial comparing mitomycin-C plus shortterm doxifluridine (Mf) versus mitomycin-C plus long-term doxifluridine plus cisplatin (MFP) after curative resection of advanced gastric cancer (AMC 0201) (NCT00296335). J Clin Oncol. 2008;26(15s; ASCO annual meeting abstract 4531).

19. Cunningham D, Allum WH, Stenning SP, Thompson JN, Van de Velde CJ, Nicolson M, et al. Perioperative chemotherapy versus surgery alone for resectable gastroesophageal cancer. N Engl $\mathrm{J}$ Med. 2006;355(1):11-20.

20. Msika S, Benhamiche AM, Tazi MA, Rat P, Faivre J. Improvement of operative mortality after curative resection for gastric cancer: population-based study. World J Surg. 2000;24(9): $1137-42$.

21. Sasako M, Sano T, Yamamoto S, Sairenji M, Arai K, Kinoshita $\mathrm{T}$, et al. Left thoracoabdominal approach versus abdominaltranshiatal approach for gastric cancer of the cardia or subcardia: a randomised controlled trial. Lancet Oncol. 2006;7(8):644-51. 